\title{
Recycling Water, Nutrients, and Waste in the Nursery Industry
}

\author{
Conrad A. Skimina ${ }^{1}$ \\ Monrovia Nursery Company, Azusa, CA 91702
}

With the increasing concerns about our environment, resources, and landfill reduction capabilities, industry is confronted with the need to recycle water, nutrients, and wastes. I will discuss sophisticated water recycling, which requires flocculation of colloidal matter, dual media filtration, chloramination, and blending. Simplified water recycling, which primarily depends on the natural settling of suspended matter, is being used more often by the nursery industry. Organic matter recycling of nursery wastes is a viable means of conserving our resources. Concomitant with water and waste recycling is nutrient conservation. Some inorganic waste and petroleum-derived organic wastes, such as perlite and plastics, have limited recycling capability, and the cost of reprocessing these materials is a problem. The cost economics indicate that recycling water, nutrients, and wastes provides a quick return on investment, conserves resources, creates an appealing public image, reduces operating costs, and protects the environment.

The United States is blessed with an abundance of natural resources. As recently as 40 years ago, we assumed our resources and energy were unlimited. We seriously recycled wastes for the first time during World War II, when there was a shortage of steel, copper, aluminum, and energy, among other necessities. Some may remember saving aluminum foil, steel cans, paper, and energy. After the war, we became complacent again and soon began wasting our resources.

In 1956 the U.S. Congress passed Public Law 84-660 (U.S. Congress, 1956) and amended it in 1972 as Public Law 92-500 (U.S. Congress, 1972). These are the Water Pollution Control Acts that set the standards for clean water. In 1970 I foresaw the problems of water waste and nitrogen pollution of the environment and began to study these problems seriously. Even as late as 1973, many universities did not take water shortages or $\mathrm{N}$ pollution of ground-

Received for publication 12 Aug. 1992. This paper was presented as the B.Y. Morrison Memorial Lecture at the 89th Annual Meeting of the American Society for Horticultural Science, Honolulu, Hawaii, 5 Aug. 1992. The cost of publishing this paper was defrayed in part by the payment of page charges. Under postal regulations, this paper therefore must be hereby marked advertisement solely to indicate this fact.

'Research Director.

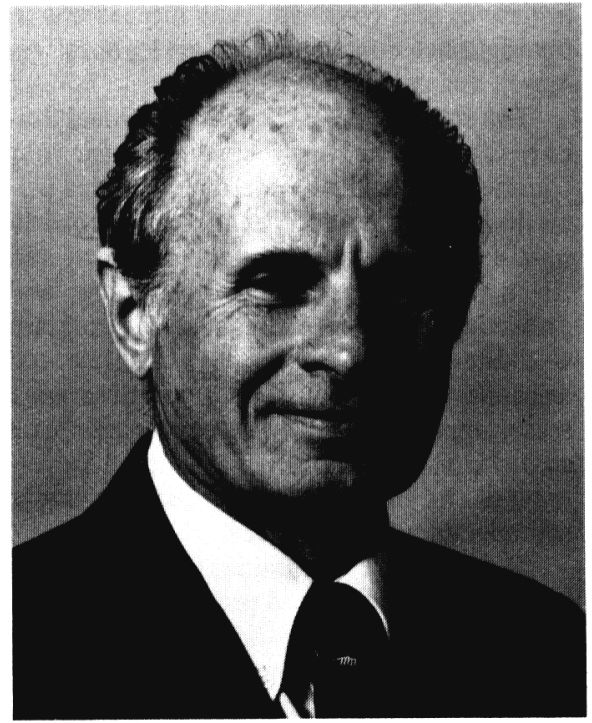

water or surface water seriously. As a consequence, I began to study $\mathrm{N}$ in the environment using lysimeters in a container nursery. I decided that recycling water was the most effective way to reduce $\mathrm{N}$ and water consumption and water runoff. After 8 years of extensive research, Monrovia Nursery Co. built a sophisticated water recycling plant to process 1.4 million gal of irrigation runoff water per day $\left(5.3 \times 10^{6}\right.$ liters $\cdot$ day $\left.^{-1}\right)$.

It has become apparent that our landfills are overburdened. During certain months, as much as $40 \%$ of the waste brought to landfills is yard waste. What a waste! Nurseries must buy organic matter to create their growing media; yet they must pay to dump their generated organic waste. Currently, at least 17 states have banned yard wastes from being sent to landfills (Glenn, 1992a). And more states have regulations restricting waste disposal, particularly yard wastes. In 1990 I studied the cost economics of recycling organic waste of biological origin. I will describe the costs and benefits of recycling these wastes.

\section{WATER RECYCLING}

Irrigation runoff, whether from overhead sprinkling, capillary tube irrigation, furrow irrigation, or hand watering, must be collected in some manner. Ideally, if the land slopes $2 \%$ to $3 \%$, open ditches or tile systems can direct the water to sedimentation pits. The sedimen- tation pit creates a quiescent zone of water that permits suspended solids to settle and lightweight, floating materials to be removed by "baffling." The sand in these pits will settle in less than $20 \mathrm{sec}$, and the silt will settle within $2 \mathrm{~h}$. By far, colloidal matter, usually clay, is the most difficult contaminant to remove from water. Either a sophisticated system of clarification or a simplified one can be used to remove colloidal matter.

\section{Sophisticated clarification}

In this system, the objective is to accelerate the removal of the colloidal matter and to "polish" the water using dual media filters. Individual clay particles, invisible to the naked eye, require 3 to 5 days to settle in quiescent water. In contrast, neutralizing the negative charge of the particles with a positively charged ion, such as aluminum from alum or ferric iron from ferric sulfate, "flocculates" or aggregates the clay particles into larger particles, thus facilitating settling. When combined with an organic polymer, the size of these aggregated particles can be increased to accelerate settling significantly. Under these conditions, particles will settle in minutes rather than days. Following flocculation, the particles are allowed to settle, and the supernatant water is "polished" by treating it with a disinfectant and filtering it through dual media filters. Dual media filters, such as those used by the drinking-water industry, consist of a layer of anthracite coal over sand over gravel. Without a coal layer above the sand, flocculated clay would quickly plug the sand, rendering it useless. The interstices of the coal permit the storage of large quantities of flocculated clay before it reaches the sand. Following filtration, some method of blending the water with fresh make-up water is necessary to recover that lost through evapotranspiration and percolation (Fig. 1).

\section{Simplified clarification}

Because sophisticated systems require more capital, many small nurseries will use a less costly system and sacrifice some clarity for ease of handling. Such a system depends on a large, preferably longitudinal reservoir, which has a long retention time to permit settling of the clay. With such a system, the only chemical outlay is the cost of chlorination or bromination. Injecting chlorine for disinfection will invariably form monochloramine because of the presence of ammonium $\mathrm{N}$ in the runoff. 